\section{Commentary: Collateral impact of the HVAD decision and the path forward}

\author{
James K. Kirklin, MD
}

Balachandran and colleagues ${ }^{1}$ have provided an elegant presentation of the circumstances, immediate impact, and potential future implications of the Medtronic decision to remove the HVAD left ventricular assist device (LVAD) from the market in June, 2021. The authors have provided historical context and their unique perspective, making this piece a "must-read" for all practitioners in this field.

Going forward, it is vital to reflect on the real limitations of these modern continuous-flow devices, which function with a small fraction of physiologic pulsatility. The current issue is not durability or effective performance; it is rather the associated adverse event profile that hinders widespread application of these devices for anything but spiraling circulatory failure. As recently as 2020, application of these devices in severe but stable (ambulatory) heart failure accounted for $<13 \%$ of implants. ${ }^{2}$ The major adverse events of stroke, device-related infection, gastrointestinal bleeding, renal dysfunction, and respiratory failure are major predictors of subsequent mortality, and, with rare exceptions, are equally as likely among patients with ambulatory heart failure as among those with inotrope dependence and/ or impending circulatory collapse. ${ }^{3}$ The Society of Thoracic Surgeons INTERMACS national mechanical circulatory support registry has provided unique insights into the powerful impact of these adverse events on not only survival but also health-related quality of life during support. ${ }^{4}$

\footnotetext{
From the Department of Surgery, University of Alabama at Birmingham (UAB), South Birmingham, Ala.

Disclosures: The author reported no conflicts of interest.

The Journal policy requires editors and reviewers to disclose conflicts of interest and to decline handling or reviewing manuscripts for which they may have a conflict of interest. The editors and reviewers of this article have no conflicts of interest.

Received for publication Oct 19, 2021; revisions received Oct 19, 2021; accepted for publication Oct 20, 2021; available ahead of print Oct 29, 2021.

Address for reprints: James K. Kirklin, MD, Division of Cardiothoracic Surgery, Kirklin Institute for Research in Surgical Outcomes (KIRSO), Department of Surgery, University of Alabama at Birmingham (UAB), ZRB 739, 703 19th St South, Birmingham, AL 35294 (E-mail: jkirklin@uabmc.edu).

J Thorac Cardiovasc Surg 2022;164:1942-3

$0022-5223 / \$ 36.00$

Copyright (c) 2021 by The American Association for Thoracic Surgery

https://doi.org/10.1016/j.jtcvs.2021.10.029
}

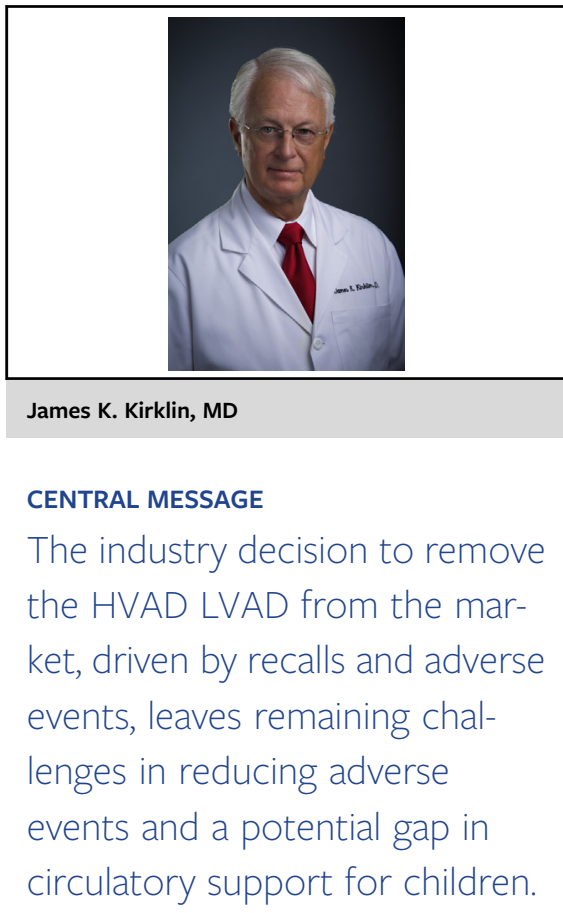

No LVAD will gain widespread application across a broader spectrum of advanced heart failure until the adverse event rates demonstrate major improvement over those recorded in the past 5 years.

An area of real concern is the pediatric population. The HVAD was not designed for small children, but the pediatric community rapidly embraced this device for adolescents and older children because of its relatively small size and the convenience of hospital discharge. ${ }^{5}$ The HeartMate 3 device is increasingly being applied in the pediatric population, but its larger size compared with the HVAD will become an immutable barrier in small children. The pediatric community has greatly benefitted from the availability of the pediatric Berlin Heart EXCOR for infants and small children, saving countless lives for $>2$ decades, ${ }^{6}$ but the extracorporeal nature of this device limits safe mobility, particularly if hospital discharge is realized in the future. Clearly, ongoing innovations are necessary in the pediatric population, but the potential looms for a domino effect of this industry decision that could impede progress in the development of smaller devices.

The authors put forth an optimistic view of the stakeholder response to this unfortunate chain of events-let's hope that young engineers and start-up device companies will receive the needed enthusiastic support from the advanced heart failure medical and surgical communities. 


\section{References}

1. Balachandran I, Frazier OH, Rogers JG. Doing the wrong thing for the right reasons: the demise of the HVAD. J Thorac Cardiovasc Surg. 2022;164:1937-41.

2. Molina EJ, Shah P, Kiernan MS, Cornwell WK III, Copeland H, Takeda K, et al. The Society of Thoracic Surgeons intermacs 2020 annual report. Ann Thorac Surg. 2021;111:778-92.

3. Kirklin JK, Pagani FD, Kormos RL, Stevenson LW, Blume ED, Myers SL, et al. Eighth annual INTERMACS report: special focus on framing the impact of adverse events. J Heart Lung Transplant. 2017;36:1080-6.

4. Grady KL, Wissman S, Naftel DC, Myers S, Gelijins A, Moskowitz A, et al. Age and gender differences and factors related to change in health-related quality of life from before to 6 months after left ventricular assist device implantation: findings from interagency registry for mechanically assisted circulatory support. J Heart Lung Transplant. 2016;35: 777-88.

5. Conway J, Miera O, Adachi I, Maeda K, Eghtesady P, Henderson HT, et al Pediatric VAD Investigators. Worldwide experience of a durable centrifugal flow pump in pediatric patients. Semin Thorac Cardiovasc Surg. 2018;30: 327-35.

6. Hetzer R, Kaufmann F, Delmo Walter EM. Paediatric mechanical circulatory support with Berlin Heart EXCOR: development and outcome of a 23-year experience. Eur J Cardiothorac Surg. 2016;50:203-10.
See Article page 1937.

\section{Commentary: Beyond data: Transparency and trust}

\section{Scott C. Silvestry, MD}

In this month's issue, Drs Balachandran and colleagues ${ }^{1}$ convey their perspective in their Expert Invited Opinion in "Doing the wrong thing for the right reasons: the demise of the HVAD," and outline the trials and tribulations of the Medtronic HeartWare HVAD left ventricular assist device (LVAD) and its removal from the world market earlier last year (August 12, 2021). Their perspective is insightful and enlightening, coming from one of the storied founding fathers of mechanical circulatory support (MCS) as well as a foundational thought leader.

In this piece, the authors describe the development of the HVAD and its progress through the bridge to transplant ADVANCE (Evaluation of the HeartWare Left Ventricular Assist Device for the Treatment of Advanced Heart Failure) trial and the tiered destination therapy ENDURANCE (A Prospective, Randomized, Controlled, Un-blinded, MultiCenter Clinical Trial to Evaluate the HeartWare Ventricular Assist System (VAS) for Destination Therapy of Advanced Heart Failure) trial and the and post-approval data and regulatory challenges. ${ }^{1}$ This story clearly showed increased

From the AdventHealth Transplant Institute, Orlando, Fla

Disclosures: The author reported consultant for Abbott, Medtronic, Abiomed, and Syncardia.

The Journal policy requires editors and reviewers to disclose conflicts of interest and to decline handling or reviewing manuscripts for which they may have a conflict of interest. The editors and reviewers of this article have no conflicts of interest.

Received for publication Dec 26, 2021; revisions received Dec 26, 2021; accepted for publication Jan 5, 2022; available ahead of print Oct 29, 2021.

Address for reprints: Scott C. Silvestry, MD, Advent Health Transplant Institute, 2415 North Orange Ave, Suite 600, Orlando, FL 32804 (E-mail: Scott.Silvestry.md@ adventhealth.com).

J Thorac Cardiovasc Surg 2022;164:1943-4

$0022-5223 / \$ 36.00$

Copyright (c) 2022 by The American Association for Thoracic Surgery

https://doi.org/10.1016/j.jtcvs.2022.01.010

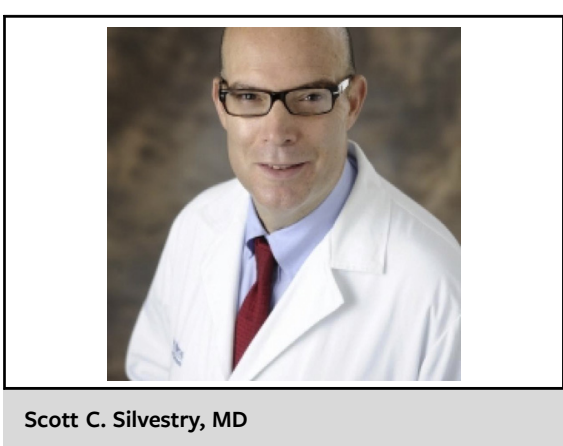

CENTRAL MESSAGE

Developing MCS devices requires collaboration to achieve clinical use while assessing riskbenefit as data accrue. The decision to withdraw a device has important implications beyond clinical use.

neurological adverse events, and a high number of Food and Drug Administration (FDA) recalls before evidence of sudden pump stoppage delivered the coup de grace prompting HVAD's market removal. Although this story and these data belong to the HeartWare LVAD, a similar arc could have occurred with any LVAD, or even general cardiac surgical device, and our community should take note of this narrative. In their article, Balachandran and coauthors weave several important lesson and themes:

1. This pump and others of its era were developed in collaboration with surgeons, cardiologists, engineers, and the origin company, HeartWare.

2. The clinical trials that delivered the pumps into wider clinical use had signals for adverse events that evolved over time and were potentially mitigated by iterations 